RUNNING HEAD: ONE-TO-ONE ALTERNATIVE PROVISION

Developing and maintaining the teacher-student relationship in one to one Alternative Provision: the tutor's experience

Wendy Fitzsimmons, Richard Trigg, Preethi Premkumar

Psychology Department, Nottingham Trent University, Nottingham, UK

Address for Correspondence:

Dr Richard Trigg

Department of Psychology

Nottingham Trent University

Nottingham NG1 4FQ

Email: Richard.trigg@ntu.ac.uk

Word count: 7389 


\section{Developing and maintaining the teacher-student relationship in one to one Alternative Provision: the tutor's experience}

This study explores and illuminates tutors' experiences of their teacher-student relationships within one-to-one alternative provision. A positive teacher-student relationship is crucial in enabling students who have been excluded from school, or are at risk of exclusion, to have positive outcomes. Yet, teachers have struggled with the emotional demands of relating to pupils with such challenging behaviour. Interpretative phenomenological analysis (IPA) was used to explore the lived experiences of the teacher-student relationships of six tutors teaching students on a one-to-one basis outside school premises, such as in the students' homes or local libraries/cafes, as part of a growing aspect of alternative provision. The IPA explored, through the lens of attachment theory, the experience of developing and maintaining these relationships. The study found that the teacher-student relationship was humanistic in nature and fundamental to student engagement in learning. However, tutors did not feel they always had the right skills or support to develop or maintain these relationships. We conclude that an understanding of attachment theory and psychodynamic concepts, together with the availability of reflective supervision, could help tutors optimise their work.

KEYWORDS: Alternative Education; Teacher Student Relationship; Attachment Behaviour; Social, Emotional and Mental Health 
RUNNING HEAD: ONE-TO-ONE ALTERNATIVE PROVISION

\section{Introduction}

Learning is a social process (Vygotsky, 1978), with relationships being fundamental to the educational experience (Giles, Smythe \& Spence, 2012). For students at risk of academic failure, the teacher-student relationship (TSR) assumes particular significance, with Downey (2008 p.57) emphasising how its importance “cannot be overstated”. Malcolm (2019 p.85) agrees, suggesting that "the relationships young people experience in alternative provision are the fundamental base from which all else is built". This view is upheld by the student voice, with students in alternative provision expressing strong TSRs as crucial to re-engagement (Nicholson \& Putwain, 2015). Similarly, pupils in mainstream schools struggling with social, emotional and mental health (SEMH) issues refer to the power of caring TSRs in restoring them to more positive trajectories (Cefai \& Cooper, 2010). Furthermore, those excluded from mainstream education report TSRs as being the most important factor in assisting them to achieve a range of positive outcomes (e.g. Michael \& Frederickson, 2013; Pomeroy, 1999).

The importance of the TSR to excluded students, or those at risk of exclusion, may seem at odds with their noted failure to access any meaningful TSRs within mainstream settings (Meo \& Parker, 2004). However, nearly $100 \%$ of excluded students are considered to have either diagnosed or undiagnosed mental health needs (Gill, Quilter-Pinner \& Swift, 2017) and, of these needs, many are increasingly being recognised as attachment disorders (DfE, 2014). Attachment theory has, over the last two decades, become one of the dominant frameworks for highlighting the foundational importance of primary relationships and understanding interpersonal dynamics (Shaver \& Mikulincer, 2011). Its prominence in understanding the relational behaviours of children and young people has led to attachment theory underpinning policy development by both the DfE (2012) and NICE (2015) in relation to education and social work. However, attachment theory has been criticised for limitations such as a lack of a strong empirical basis (Smith, Cameron, \& Reimer, 2017), its overly 
RUNNING HEAD: ONE-TO-ONE ALTERNATIVE PROVISION

deterministic approach (Duschinsky, Greco, \& Solomon, 2015) and prescriptive classifications that can mischaracterise (Main, Hesse \& Hesse, 2011). Yet, despite these criticisms, it currently remains a leading approach to understanding and researching relational behaviour.

Derived from the work of John Bowlby (Bowlby, 1969), attachment theory suggests that infants whose early relationships fail to meet their emotional and security needs develop inner working models (IWM) containing negative mental representations of themselves and others (Bretherton \& Munholland, 1999). Unlike securely attached children, the insecurely attached child has a continuing fear of its needs not being understood or met, resulting in high anxiety which is dealt with by the development of psychological defence mechanisms such as avoidance, disassociation, hyperactivity or projecting feelings onto others (Dover, 2009). Insecure attachment, when combined with other risk factors such as low income and chaotic home environments, creates a high risk for both internalising (damaging to the self) and externalising (damaging to others) behavioural problems, together with difficulties in forming close relationships (Kennedy \& Kennedy, 2004). However, a TSR which feels secure can begin to meet some of the students' relational needs, enabling them to manage their anxiety, ameliorate their behaviour and increase their capacity to learn (Bergin \& Bergin, 2009).

Creating positive TSRs is of key relevance to the growing number of tutors educating students on a one to one basis within alternative provision. Alternative provision (AP) provides education "for pupils who, because of exclusion, illness or other reasons, would not otherwise receive suitable education" (DfE, 2013 p. 3). One-to-one tutors often work with their students in the student's home or at a local library/cafe depending on the level of student risk and availability of nearby community facilities. Tutoring usually occurs in blocks of two hours, with some students having a maximum of four hours per week (depending on levels of funding); this being their only remaining form of educational provision. Cook (2005, p. 90) 


\section{RUNNING HEAD: ONE-TO-ONE ALTERNATIVE PROVISION}

aptly describes these vulnerable young people as "the hard to reach, hard to teach, most alienated, most vulnerable and those at the end of the line - for whom nothing has worked so far".

Students are placed within one-to-one tuition, as opposed to a group setting within AP, for a variety of reasons, including having previously had relational difficulties with teachers and peers. One-to-one provision has been criticised for doing little to address the problems some young people have in interacting with their peers (Pirrie et al., 2009), but Jennings \& Greenberg (2009) consider teachers with high levels of social and emotional competence can model, develop and improve a student's social and emotional outcomes. Whereas teachers within a secondary school environment will only become 'ad hoc attachment figures' (Kobac \& Madsen, 2008), one-to-one tutor relationships will have a stronger 'attachment component' (Cassidy, 2008), thereby increasing the effect of a positive relationship. This pivotal opportunity for tutors to create a positive TSR becomes even more significant, given Sabol \& Pianta's (2012) warnings of the particularly adverse outcomes of negative TSRs for vulnerable students. Indeed, students who fail to engage with their tutors in one-to-one provision struggle to find further educational provision and are at high risk of becoming 'not in employment, education or training' (NEET) (Tate \& Greatbatch, 2017), with its consequent potentially damaging outcomes, such as mental health difficulties, delinquency and homelessness issues (e.g. Daniels et al., 2003).

Tutors may endeavour to create positive TSRs with their pupils, yet relationships between teachers and troubled students are frequently characterised by conflict (Nurmi, 2012). Teachers find that maintaining care and empathy when faced with challenging or distressing behaviours is immensely difficult, with Cooper $(2010, \mathrm{p} 4)$ confirming that "no other problem is associated with such a level of frustration, fear, anger and blame". The teacher's own IWM will also influence their ability to respond to a student's needs, with 


\section{RUNNING HEAD: ONE-TO-ONE ALTERNATIVE PROVISION}

insecurely attached teachers being less able to respond with warmth, security and sensitivity to challenging behaviour (Kennedy \& Kennedy, 2004). Teachers who do become relationally available to such pupils will be subject to a high level of 'emotional labour' (Hochschild, 1983). As Kidger et al. (2010) found, teachers supporting students with emotional health and well-being (EHWB) needs reported feeling emotionally drained themselves and reluctant to engage with the students due to their own needs being neglected.

Qualitative studies on the relationship between teachers and students with SEMH difficulties offer insight into their relational dynamics. Research into the SEMH student voice includes that of Pomeroy (1999), who investigated the TSRs of excluded students. SEMH students characterised their 'ideal model of the TSR' as being a positive relationship containing care from the teacher through knowing, listening, talking and explaining things to them. They wanted 'almost adult to adult relationships' based on mutual respect, with the teachers meeting their pastoral needs rather than adopting the punitive approaches used in schools. Browne (2013) confirmed these relationship themes, whilst also identifying trust as key to SEMH students being able to develop reciprocal relationships with their teachers. These tenets are reflective of a humanistic approach to teaching which considers learning and personal growth to occur through an empathic, congruent TSR, focussing on the holistic needs of the child rather than individual aspects (Kazanjian \& Choi, 2016). Whilst all students can benefit from a positive TSR (e.g. Sabol \& Pianta, 2012), the particular focus that excluded students place on this relationship may reflect the additional difficulties they face in the classroom because of their historical lack of access to positive relationships. These difficulties include their greater inability to self-regulate their emotions (Van Bergen \& Salmon, 2010) to trust others, to motivate themselves and to bear the frustrations of a task's difficulty (Murray, 2009), without the mediation of an adult they perceive to hold them in positive regard. 
RUNNING HEAD: ONE-TO-ONE ALTERNATIVE PROVISION

Research into the TSR lived experience with SEMH students from the perspective of the teacher have centred on stress and well-being or the experience of negative behaviour (e.g. Partridge, 2012; Dennison, 2017). However, understanding how the teacher develops and maintains a positive relationship with their student is key to the successful implementation of one-to-one AP. Consequently, this study aims to explore the AP tutor's experience of their relationships with their SEMH students, in terms of their perceived importance, the positive and negative aspects, and the strategies used to develop and maintain them. The resulting data are analysed through the lens of attachment theory due to the illumination this framework can offer to complex relationship dynamics.

\section{Method}

The methodology used for this study was Interpretative Phenomenological Analysis (IPA) of six semi-structured interviews with one-to-one tutors undertaken by the researcher, who was also a one-to-one tutor for the same organisation. There are benefits of the researcher's closeness to the research, such as access to participants and potentially more open interviews due to participants' knowledge of the researcher's role. However, the researcher's proximity may also have influenced the preparation of the interview schedule and the data analysis as "one cannot escape the personal interpretations brought to qualitative data analysis" (Creswell, 2009, p. 18). To bring awareness to how their own beliefs and views impacted on the research, the researcher reflected honestly and vigilantly on their own positionality, recognising and setting aside their own presuppositions throughout the project, particularly during analysis, to enable "the analytic goal of attending to the participants' accounts with an open mind" (Starks \& Trinidad, 2007 p. 1430). This process, known as 'bracketing' (Husserl, 1999) was assisted by making notes at key decision times, during analysis, to review the influence of the researcher's perspectives. In addition, the researcher read the transcripts many times to ensure the participants' understanding of a situation was taken (Smith, 2007). 
RUNNING HEAD: ONE-TO-ONE ALTERNATIVE PROVISION

When identifying themes, directories of the participants' phrases supporting the chosen themes were compiled to ensure that the themes fitted with the words of the participants (Smith, 2007) rather than with the researcher's pre-existing assumptions.

\section{Participants}

Participants were recruited via an email sent to all 120 tutors employed by a regional independent alternative provider of one-to-one tutoring. The inclusion criterion was to have at least a year's experience of tutoring SEMH students. Following Smith, Flowers and Larkin's (2009) recommendations that sample sizes should be small enough to enable idiographic analysis, six participants were recruited. Of the 18 who replied to the email, a purposive sample was chosen (see Table 1) to ensure the homogeneity required by IPA to elicit the rich, detailed accounts required; of the TSRs of these particular tutors, working in this specific context at this particular time (Smith et al., 2009). To this end, only tutors teaching secondary school students were selected, as introducing additional factors (e.g. student age differences) may have created unwanted breadth. Also, four of the six participants were working in the same region under the same case manager. This ensured that participants were comparable in terms of their work environment, the level of support being offered to them and type of students being referred, enabling an in-depth, exploratory focus on the tutors' TSRs.

Insert Table 1 here 
RUNNING HEAD: ONE-TO-ONE ALTERNATIVE PROVISION

\section{Materials}

An interview schedule and prompt sheet were prepared to address the primary research question and served as a guide during the interview. The schedule explored the tutors' views on how important they considered their TSRs, their experience of both good and difficult relationships and how they had initiated and developed them. It also probed occasions where tutors felt they had been unable to develop a TSR. This enabled the research aims to be addressed, whilst also allowing for flexibility and freedom to explore areas of interest in more detail as and when they were presented by participants (Pietkiewicz \& Smith, 2014). Participants were given an overview of what they would be interviewed about in advance with the intention of allowing reflexivity prior to meeting and enhanced interview depth.

\section{Procedure}

The study had ethical approval from Nottingham Trent University and followed the British Psychological Society ethical guidelines for research with human participants. Information about the study was sent to participants prior to interview, with written consent gained at the interview itself. The interviews were held at either the researcher's office or participant's home, whichever most suited the participant. In-depth semi-structured interviews were used to collect the data, and these were audio-recorded in full. At the end of the interview, all participants were debriefed and their right to withdraw reaffirmed.

\section{Analytic Procedure}

The interviews lasted from 73 to 95 minutes and were digitally recorded and transcribed verbatim. IPA was used to explore the data and better understand the essence of the tutor's relational experience with their student. As the researcher worked in the same tutoring role, care was taken to ensure their own perceptions and experiences did not influence the 
RUNNING HEAD: ONE-TO-ONE ALTERNATIVE PROVISION

emergent themes through use of the bracketing techniques described earlier.

Analysis of the data followed a four-stage process drawn from a combination of analytic steps described by Larkin and Thompson (2012) and Pietkiewicz and Smith (2014). Each participant's transcript was visited separately with an initial examination of the descriptive, then linguistic, constructs in the left-hand margins. Conceptual meanings were then noted in the right-hand margin during the process of interpretation. Several superordinate and subordinate themes emerged during this phase, but only those connected to the research aims were carried through to full development (Smith et al., 2009). This first stage of the process was inductive and data driven. It was only when the themes had fully emerged that the process became reductive and the data were analysed through the lens of attachment theory, in an effort to try and understand the participants' experiences through this pre-existing relational framework.

\section{Results and Discussion}

The interview data elicited three superordinate themes covering issues related to the experience of AP tutors and the challenges they faced in their role. One of these superordinate themes, containing four subordinate themes, specifically related to the way in which tutors described the TSR and the key processes underpinning its development and maintenance, within the context of AP. These four subordinate themes were labelled as: connecting and tuning in; the look and feel of the relationship; bringing the whole person; and struggling with disconnection.

\section{Theme 1: Connecting and tuning in}

All tutors were unanimous about the importance of developing a relationship with their student as a pre-requisite to achieving progress: 


\section{RUNNING HEAD: ONE-TO-ONE ALTERNATIVE PROVISION}

"absolutely crucial. It's not possible to work with a young person one-to-one if there isn't some kind of shared interest, mutual interest. Yeah, I think it's crucial." - Cilla

“Oh, if you've got no relationship, there's no purpose. That's the way I feel. The quicker you can find the hook with the students, the quicker you get a relationship going with them." - Frances

Not only are the tutors adamant about the centrality of the relationship to learning, but they perceive the relationship to be about finding a 'mutual interest' or connection (Bennett, 2003). Connection, by its nature, is reciprocal thus the tutors are looking to actively engage with their student rather than viewing them as a passive recipient. Frances perceives the connection or 'hook' as enabling her to initiate the relationship development and her active search for the hook resonates with Giles's (2008) view that the teacher is responsible for initiating the relationship. If we interpret the use of the word 'hook' as a 'lure', this might suggest that SEMH students resist connecting of their own volition and Frances' need to find it 'quickly' reinforces the tutors' views that a relationship needs to be in place before learning can begin. It needs to be attended to as the first priority. Consequently, this is a potentially challenging experience for insecurely attached students, as Andy's account illustrates:

\footnotetext{
"some of them you can (pause) kind of... draw them in. But some of them just go, no, no. But some of them, when they're saying that, they want you to give them something else and you've got to say, what is that something else?"
}

Whilst Andy agrees some students can be hooked or 'drawn' into a relationship, he also illustrates that other students resist, requiring him to uncover the 'something else' they need that will allow the relationship to develop. Needing 'something else' that is not clear within the present resonates with an insecurely attached child carrying unmet needs from the past, which Geddes (2006) suggests are unconscious in nature. Marlowe (2011) recommends focusing on the relationship to understand these unconscious needs, as it gives better access 


\section{RUNNING HEAD: ONE-TO-ONE ALTERNATIVE PROVISION}

to the child's internal "unobservable" world. Martin describes his process of getting to know the student's world:

“...you're feeling your way, and you're working blind, just to get a feel of what they're like... what will motivate them, what won't motivate them, you know. And what their demands are. I think that you tune your listening skills differently. You're listening for the nuances of somebody's conversation and what they're telling you, and what might be going on in their particular world." - Martin

'Working blind' echoes Marlowe's thoughts that the student's world is 'unobservable' and only by deeply engaging all his senses can Martin begin to understand 'what they're like'. The students' unconscious communications are implied by Martin's description of 'listening to the nuances' and having to gauge not just the student, but the student's 'world' such as their family relationships and home life to discover what may be impacting on the child's ability to connect. As with Frances, the need to communicate this sensitivity quickly via the ability to 'tune in' resonated with all the tutors' accounts. Andy's quote illustrates the importance of making this early connection through the intense pressure he feels prior to the first session:

"my apprehension might be seen as negative but it's more like waiting to go and play a big football match or do a big presentation. You're apprehensive because you want to perform well... take in everything which you can then maybe... well, it's all got to go in, hasn't it, everything you get to take in on that first session is useful." - Andy

The need to glean every bit of information possible, 'it's all got to go in', reaffirms the tutors' view that understanding the student is crucial to forming a relationship, whilst also intimating a fragility to potential connection - that not 'performing well' risks failure. This resonates with Seagar's (2014) view that whilst exhibiting empathy is a crucial attachment behaviour, it can be easily ruptured by a moment of insensitivity or being 'out of tune'. Thus, knowledge not only assists in fostering an emotional connection, but can also guard against losing it. 


\section{RUNNING HEAD: ONE-TO-ONE ALTERNATIVE PROVISION}

Often, when faced with a student's challenging behaviour, teachers can react unconsciously from their own inner working model (IWM), rather than responding sensitively to the behaviour's underlying meaning thereby reinforcing the student's existing IWM (Geddes, 2006) and risking the loss of a hard-won connection. However, the tutors' narratives suggested that the tutors reflected deeply on their responses to students, resonating with the view that the caregiver's capacity for reflection is more influential than their attachment style in predicting positive outcomes (Slade, 2008).

\section{Theme 2: The look and feel of the relationship}

All tutors had forged positive connections with students, with some developing into rewarding relationships. Frances's extract illuminates this point particularly well:

"Yes, I had a lovely year 11 girl. She was a nervous student who couldn't go into school. She was absolutely lovely, and we had a wonderful relationship." - Frances

Frances believes that, despite the student's anxiety, they had formed a very positive, reciprocal relationship. However, most relationships were described by tutors as requiring high levels of pastoral and learning support, demanding hard work rather than offering reward. In a minority of cases, it was also clear from the tutors that whilst they could connect with their students, being able to like them was not always achieved:

"I don't really like him. I think he does like me but he would never admit it. If he didn't like me, he would vote with his feet and just not come out (of his home for a lesson). So he clearly does... It's hard" - Grace

Despite Grace not liking the student, the student apparently likes Grace enough to 'come out' although this is the only affirmative indication Grace has of their connection. The lack of positive feelings on both sides makes this relationship 'hard'. This resonates with research which shows that whilst good TSRs are particularly important for 'at risk' students, they are 


\section{RUNNING HEAD: ONE-TO-ONE ALTERNATIVE PROVISION}

more likely to develop negative ones due to their insecure attachment (Bergin \& Bergin, 2009). Grace will also be influenced by her own relational model, besides being faced with the task of dealing with her student's challenging behaviour, resulting in her struggle to 'like him'. Working within this context of negative emotions, forging TSRs involves high emotional labour (Zapf, 2002) which is illustrated in Martin's response:

“They didn't get on with their school relationships, so, why should they get on with us? So, I think we do have to give and take or give, give."

Martin's acceptance of his students' struggles with relationships indicates he doesn't take them personally, thus alleviating his emotional stress (Nash, Schlösser \& Scarr, 2016). His sense he needs to 'give, give' to make it work highlights that whilst tutors look for reciprocity in their student relationships, it requires far higher investment from the tutor to ensure it is viable, particularly if they don't 'get on'. However, if liking each other is a challenge, Pomeroy (1999) found that if a student felt cared for, this increased their ability to work and learn. All the tutor accounts are permeated with care for their students, from their efforts to personalise the learning to the student's interests, to hearing and dealing with their concerns, to their empathic responses to challenging behaviour. Whilst Mihalas and colleagues (2009) contend that many SEMH students struggle to internalise care, Seagar (2014) posits that every child can subjectively feel the difference between being cared for or not being cared for in a live relationship. Care, within attachment theory, can be understood as satisfying early unmet needs within the insecurely attached child, thus, feeling cared for, rather than necessarily being 'liked', would seem to enable tutor/student connection. Satisfying unmet 'needs' and 'demands' was a strong theme within the data with Andy's extract describing how his TSRs vary and how, at their most basic, relationships are about 'meeting the need': 
RUNNING HEAD: ONE-TO-ONE ALTERNATIVE PROVISION

"Like when you initially meet the student, you get a vibe as to what they're like and sometimes there can be an instant rapport, sometimes that rapport comes after a few weeks, maybe months and sometimes you're just meeting the need and that rapport never really materialises. It's just that the student wants something and you're giving it to them and as long as you do that, they're happy."

Andy describes a 'rapport' as something which makes the relationship mutual whereas 'meeting the need' requires him to give something to the student without a sense of reciprocity. Whereas relationships based on humanistic principles centre on a sharing of responsibility for the educational interactions (Hare, 2005), meeting the need evokes a behavioural approach of an educational transaction from tutor to student whereby the student is a passive recipient within the relationship (Tompkins, 2005). Andy's student may be 'happy' as Andy is providing the secure base he needs to alleviate his stress, but he finds himself with little capacity left for further engagement. This may be positive for the student, but the lack of reciprocation within the TSR can become problematic for tutors:

"Quite often I do the best I can but sometimes, I may not put 100\% into them because I think "you don't deserve it". But on the other hand, I know the more I invest, the easier and more positive working relationship we should have" - Grace

Whereas strong, positive relationships can motivate teachers to invest time and energy in their students (Spilt et al., 2012), Grace's 'sometimes' negative feelings about a student interferes with her ability to 'invest' in them despite her knowing the relationship will improve if she does, thus creating her dilemma. Working with SEMH students is emotionally draining, but particularly so if you're presenting an emotional front incongruent with how you feel (Kidger et al., 2010). The emotional dissonance Grace feels means that higher levels of energy will be required to invest further in the TSR and may be the reason she resists, despite knowing it will make the relationship better. 
RUNNING HEAD: ONE-TO-ONE ALTERNATIVE PROVISION

\section{Theme 3: Bringing the whole person}

Humanistic relationships are underpinned by two main constructs: congruence and empathy (Rogers, 1980). Congruence refers to the tutor being 'real' with no professional façade (Kazanjian \& Choi, 2016), which resonated with the tutors' own emphasis on being genuine and bringing themselves to their TSR, echoing Palmer's (1997, p.1) belief that to maintain relational connectedness, teachers need to "teach out of who they are":

\footnotetext{
"you have to work within your own personality completely, really for it to work." Rachael

"I think there has to be a connection. I've used humour, personally, I've used my own personality, my own strengths.... I think if you share a bit of yourself, it encourages them to get to know the person behind the label of tutor." - Cilla
}

These tutors believe that for a connection to work it must be based on the reality of their personalities or their 'true self' (Palmer, 2004). Cilla is aware that students may not be able to see her 'true self' due to their preconceptions of her 'label' of tutor. Labelling encourages stereotypical judgements and given AP students' frequent negative experiences of teachers and authority figures (Delaney, 2009), she wants them to get to know her real self or 'person'. Bringing the person or 'self' to the TSR enhances the teacher's ability to relationally connect as Hart (2001, p50) considers the 'authenticity of the meeting' matters as much as the content. Yet, Giles (2008) considers that bringing the self creates the uncertainties and risks of an 'unscripted play' and that caring for a student in an uncontrolled environment can create tension around the crossing of professional boundaries. The theme of boundaries resonated strongly throughout the tutors' accounts.

\footnotetext{
“...You can't get to the child till you've talked about what crisis they're [the parents/carers] going through at the moment. And what I think you're seeing with some - our social services have found themselves increasingly stretched. I've found myself
} 
RUNNING HEAD: ONE-TO-ONE ALTERNATIVE PROVISION

progressively more drawn into "well, we were meant to have a social worker, ... And now, we don't see hide nor hair of anybody. So, I have this form through the post, and I can't read. Can you help me with it? What should I do? Will you sort this out?" ... But what do you do? You can't turn away." - Martin

Martin illustrates his dilemma over what he feels he needs to do versus what, professionally, he actually should do to 'get to the child', the latter being interpreted as being able to engage the child in learning. Martin feels drawn to help with the family issues surrounding the child. Empathy enables a person to experience the feelings of another's world as if it were their own (Rogers, 1980) which makes it difficult for Martin, as if he remains congruent to his own self he can't 'turn away' even if it means crossing a professional boundary. To be able to 'turn away' would mean Martin emotionally distancing himself from the child and the child's family but the human connection is what the student is seeking to enable them to learn. The tensions of these paradoxical pressures are challenging and complex (Hare, 2005) which is reflected in Martin's uncertainty over how to proceed:

"we're not especially trained to know how to deal with situations where the family is drawing you into their world. And I personally feel that we need to respond... before we start the actual business of, in this case, working on Key Stage 3 English.”

Martin has clarity that these family issues 'need to be responded to' before learning can begin, recognising that a child's physiological and safety needs come before their readiness to learn (Maslow, 1954). However, given the dissonance between his personal and professional boundaries, Martin is uncertain as to his role and would like 'training to deal with the situation'. The tutors' accounts were replete with examples where the TSRs were fragile due to the difficulty of working within complex family environments which Martin describes as:

\footnotetext{
"a world that you want to take an MP and say, "Look at this world. Social services were withdrawn from this family. They're on their own. There's only me left."
} 


\section{RUNNING HEAD: ONE-TO-ONE ALTERNATIVE PROVISION}

Tutors often described working in isolated and emotionally painful situations where Wright (2009) considers teachers can respond in two ways: either by emotionally distancing themselves from the child's distress to emotionally protect themselves, or to bear witness to their student's pain and tolerate their damaging behaviours. Which choice tutors made appeared to depend on the quality of the TSR. Rachael, for example, had two complex students with difficult family situations. With one, she initiated a disconnection of the TSR, yet with the other she was "breaking all the laws" to enable it to continue. Reflecting on this difference, Rachael felt the latter student "was willing to have a relationship with me". With the other, "there was nothing coming back". Thus, it was the reciprocity within the TSR that enabled Rachael to face the emotional demands of the situation. Indeed, tutors were more likely to stop teaching those they perceived to be relationally unavailable thus potentially reinforcing the educational disadvantage of students with the greatest attachment difficulties.

\section{Theme 4: Struggling with disconnection}

Whilst failure to initiate a relationship with a student was rare, every tutor had experienced a situation where they had found an inability to connect. The common thread throughout these accounts revolved around difficulties in accounting for what precisely the issues were or how the disconnect came about, together with the consequent reflection and difficult feelings that needed to be processed. Both Andy and Frances are describing students that they decided they would not be able to work with, after initial sessions:

"this girl - it was just like it was already a closed shop... and so sometimes you're thinking, I haven't got a key to unlock this one... it makes you feel bad as a professional that you couldn't have reached that person" - Andy

\footnotetext{
“Because I can't say that I disliked him. It wasn't that I disliked him. It was just I knew instinctively that I wasn't going to be able to do him any good... It was something underlying. It was just something deeper..”- Frances
} 


\section{RUNNING HEAD: ONE-TO-ONE ALTERNATIVE PROVISION}

Andy's intuition was that the girl was not open to entering into a TSR. Attachment theory suggests that a student who is a 'closed shop' may have emotionally shut down as a psychological defence mechanism, most likely occurring with students who have disorganised attachment (Perry, 2001). Because Andy perceived she was 'closed', his experience told him he didn't have the ability, or 'key', within his skill set to find a way of 'drawing' her in. On the premise that humanistic relationship connections "can only be modelled and invited, ... not commanded" (Bennett, 1997, p.5), there is little Andy can do though it leaves him feeling "bad as a professional" that he couldn't "reach" her; the 'reach' resonating with Frances' 'hook' in the Connecting theme, emphasising the perceived emotional distance of SEMH students. Frances' concern did not appear to be about connecting, but about doing him some 'good'. Most teachers come to the profession with a desire to perform meaningful work (Razer \& Friedman, 2013) and her professional 'instinct' is telling her this will not be possible. Frances' decision not to work with the student was based on her professional integrity and not taken lightly, which profoundly affects Frances, as evident from the following quote:

\footnotetext{
"I didn't know whether to feel let down with myself because I knew I couldn't work with him. I questioned my motive sometimes and maybe I think too deeply. Was it me and not him or was it him and not me? But like I say, I felt floundered to be honest because it's never happened before... I wasn't fine.. when you know something is not working you internalise it"
}

Frances deeply reflects over whether her decision was the right one, and she voices her difficulty in understanding whether the reason it wouldn't work were due to feelings belonging to her or to the child. This is a common occurrence for teachers working with troubled students as the emotional state of the child can be 'transferred' from the child to the adult through unconscious factors within the teacher (Mintz, 2007). Mintz (2007) suggests teachers should be educated in these transference dynamics as awareness of these issues 


\section{RUNNING HEAD: ONE-TO-ONE ALTERNATIVE PROVISION}

allows the teacher to appraise a situation more accurately and make informed decisions. However, without this knowledge, Frances can't bring the issue to the surface so it remains 'underlying', thus making her 'flounder' and 'internalise' her anxiety. When difficult emotions aren't understood, they can't be processed, leading to them being internalised which can impact the teacher psychologically and contribute to burnout (Riley, 2010). As both Andy's and Frances' accounts show, their internal reflections couldn't resolve the issues regarding their inability to connect, illustrating that teachers sometimes need help in understanding their responses to student behaviours as well as emotional support in processing them (Dennison, 2017).

Contrary to Frances' unconscious reasoning for disconnection, Martin's reasons for not being able to connect with his student were very clear:

"I've said to the case manager, "I'm going to have to stand down on this, because I'm feeling threatened by this particular student. I figured I was not the right person for that particular student. It's about the eyes. It's what's behind... If I can't see behind the eyes, and that's a kind of metaphor in a way for something."

Martin realises that his feelings of being threatened were somehow related to not being able to see 'behind the student's eyes', which can be interpreted as the intention or emotion behind the student's threatening behaviour. He resolved the cognitive dissonance of 'standing down' rather than carrying on by telling himself he was not the 'right person'. Wright (2009) sees this discourse as enabling him to emotionally distance himself from the student whilst creating comfort and psychological stability for himself. However, this discourse doesn't fully enable him to settle his uncomfortable feelings:

\footnotetext{
"I don't cope with aggression. That's my Achilles heel really. I mean, I know there are some tutors - I'm thinking of one of ours, an ex-colleague of ours who's brilliant with the big, tough guys. Ray. Yeah. Ray would just have a way with them, and I admire and respect him for that. I can't do that." - Martin
} 


\section{RUNNING HEAD: ONE-TO-ONE ALTERNATIVE PROVISION}

By referencing his inability to deal with aggressive students as his 'Achille's heel', Martin feels it to be a weakness or deficiency within himself and he compares himself unfavourably to Ray who he 'admires' for having this capability. Yet, most tutors felt there was a specific manifestation of challenging behaviour in students they excelled in managing, such as selfharm or aggression, suggesting there were certain behaviours they felt they could successfully 'contain' i.e. enable the student to express their emotions while making them feel supported and safe (Bion, 1962). The provision of emotional containment is an essential aspect of an effective relationship (Bion, 1962), but becomes more difficult as behaviour becomes more challenging. A teacher's capacity to contain a student's feelings will reflect their own experience of containment, both from the past and also within the present. Partridge (2012) found that the anxieties of pupils could be contained by staff whose anxieties were likewise contained by colleagues or professional support. If Martin had access to a 'secure and containing forum' (McLoughlin, 2010 p.238) where he could discuss and understand the meaning underlying a student's aggressive behaviour and process the emotions it provoked within him, he could develop his capacity for working with aggressive students and avoid future disconnections of this nature.

\section{Interpretive Summary}

This research set out to generate a rich understanding of the tutor's lived experience of their one-to-one relationships with SEMH students and the challenges they faced in developing and maintaining the TSR. The tutors' descriptions of their relationships illustrated that they were humanistic in nature. Tutors looked for connection and reciprocity in their TSRs, whilst offering their students empathy and care through both their personal and professional interactions. This suggests that tutors found developing a holistic relational connection with this very challenging cohort of students, facilitated more productive learning than focusing on 


\section{RUNNING HEAD: ONE-TO-ONE ALTERNATIVE PROVISION}

the student's behaviour and its management.

This research resonated with the student voice (e.g. Pomeroy, 1999), by establishing that tutors also recognised the TSR to be fundamental to student learning. This is illustrated by the extent to which tutors thought about, attended to and reflected upon the TSR and the deep concern felt when they were unable to connect. Whilst, in most cases, connections were made, tutors found their TSRs varied in terms of student reciprocity and the emotional labour the TSR demanded, with some TSRs being purely transactional due to the passivity of the student. This variance in relational responsiveness would seem to be reflective of SEMH being a heterogeneous category (Carroll \& Hurry, 2018), with the accompanying attachment behaviours forming a wide spectrum. The tutors' belief in the significance of the TSR, together with its importance in achieving positive outcomes and its humanistic nature is resonant of the therapeutic alliance (Rogers, 1980). Therefore, it may be useful to explore the therapeutic literature to understand whether it may offer useful insights into the development and maintenance of TSRs.

Affirming previous research on emotional labour, tutors considered TSRs to require a high emotional investment throughout. Most students required emotional labour for both the initiation and maintenance of a connection due to their challenging behaviours and the tutor's difficulty in interpreting their unconscious demands (Geddes, 2006). The most demanding were a significant minority of students who struggled to reciprocate and/or were found difficult to 'like'. The process of the tutor giving but not 'getting back' (Salter-Jones, 2012), made it difficult for them to provide the emotional investment needed to either improve, or continue with, the TSR.

Similarly, tutors sometimes discontinued with the TSR due to the lack of clarity over, and the demands on, both their personal and professional boundaries when working within complex family situations. This disconnection resonates with Cook's (2005) description of 


\section{RUNNING HEAD: ONE-TO-ONE ALTERNATIVE PROVISION}

the 'hard to reach' and reflects the very difficult home lives of many excluded students who have commonly experienced family breakdown, violence/abuse and poor relationships (Parsons, 1999). The protective factor preventing tutor disconnection was the strength of the TSR; its reciprocity potentially giving tutors enough emotional reward to bear the 'human cost' (Wright, 2009) of remaining present. However, this reliance on relational reciprocity to sustain the TSR disadvantages those students with insecure attachment styles, therefore tutors need other means of support to ensure they have the emotional energy needed to preserve the relationship. Partridge (2012) describes how staff can be emotionally replenished through feeling contained and having space to offload, process and reflect on difficult feelings. Roffey (2012) recommends recognising and valuing the tutor's work, whilst Dover (2009) suggests explaining to tutors why students can find reciprocity hard, whilst assuring them that providing positive learning experiences offers valuable therapeutic input. These strategies to preserve tutor well-being together with a re-framing of the TSR role from being purely academic to being relational, as well as academic, with tutors appreciating the need and purpose of this, will increase its sustainability and provide greater satisfaction (Kazanjian \& Choi, 2016).

In a minority of cases, tutors felt they couldn't connect, or didn't want to connect, with a student for reasons they were aware of e.g. aggression, or for reasons they couldn't fully explain. Either of these situations produced difficult emotional responses within the tutor which they struggled to fully understand; suggestive of unconscious feelings which had not been fully processed. Dennison (2017) states that when issues involve unconscious processes, an understanding of psychodynamic concepts such as projection and transference is particularly useful, with Sabol and Pianta (2012) considering reflection-based interventions to significantly improve the quality of TSRs. Thus, taken with the findings above, this study affirms previous research calling for teacher support through knowledge of psychodynamic 


\section{RUNNING HEAD: ONE-TO-ONE ALTERNATIVE PROVISION}

theory together with strategies to maintain their EHWB needs such as reflective supervision. This will enable tutors to sustain the emotional energy needed and to have the emotional containment and support to reflect on, and process, the strong emotions evoked by their students (Bibby, 2010; Willis \& Baines, 2018).

Whilst there are critics of teachers being taken down the path of caring relationships and therapeutic input (e.g. Ecclestone \& Hayes, 2009), one-to-one tutors have a duty of care to vulnerable students who either already exhibit mental health issues or are at high risk of developing them (Gill et al., 2017). These support mechanisms would therefore reduce risk of harm and optimise tutors' abilities to provide students with a secure base. It would help them to refrain from responding in ways that reinforce the student's negative relationship expectations, thereby providing an opportunity for them to reframe their IWM (Geddes, 2006). It would also reduce tutor stress, reduce their chances of student disconnection and broaden the types of student they feel able to contain, whilst also adding meaning to their work. Most importantly, it will help them effectively bridge the relational gap preventing the student from engaging with learning.

This study is limited by the assumption that the TSR has come to the fore due to the nature of the SEMH student rather than the teaching framework of one to one tutoring. Further research could examine how the data differs with non-SEMH students. Also, whilst a homogenous sample was appropriate for the IPA methodology, the similar ages of the tutors and having the same case manager may have impacted on the findings. Finally, whilst this small sample of tutors has offered a rich account of their TSRs and has allowed us to draw conclusions on conceptual and theoretical grounds, caution needs to be exercised in generalising these findings to wider populations.

This research illustrates that productive teaching relationships with SEMH students in AP are different to those predominantly offered by the behaviouristic approach in schools. 


\section{RUNNING HEAD: ONE-TO-ONE ALTERNATIVE PROVISION}

Future research could consider how tutors within AP or indeed, teachers within mainstream environments can be supported to create humanistic relationships with SEMH students and whether these can improve student learning and assist behavioural change. In addition, the benefits of understanding attachment theory and psychodynamic concepts, together with supervision for those working with SEMH students such as AP tutors, teaching assistants and behaviour mentors in schools should be evaluated (e.g. McLoughlin, 2010).

\section{Conclusion}

In conclusion, the six tutors in this study were unanimous in their belief that developing a TSR was a pre-requisite to students making academic progression within alternative provision. Analysing the data through an attachment lens highlighted how a tutor's ability to 'tune in' to their student's IWM, together with their ability to reflect, was key to developing this relationship, enabling them to respond sensitively to a student's often unconscious 'demands'. However, the study also highlighted how a tutor's sensitivity and reflection could only go so far. Whilst a minority of TSRs were found to be rewarding, the majority required high levels of emotional investment, with tutors sometimes feeling they did not have the right skills, the necessary emotional energy or feel supported enough, to initiate the relationship or maintain it over time. It was also clear in their initial and later teaching sessions, tutors made decisions, both consciously and unconsciously, as to whether a productive working relationship was possible, with each having experiences where they could not bridge the tutor/student relational divide. If we are to accept the tutors' view of the TSR as the gateway to student learning, it would seem vital they receive the help they need to bridge that divide. This study, and previous research, suggests this support should be two-fold:

I. an understanding of attachment theory and psychodynamic concepts to increase tutor awareness of the relational dynamics within their TSRs 


\section{RUNNING HEAD: ONE-TO-ONE ALTERNATIVE PROVISION}

II. care of tutor EHWB needs, including supervision to reflect on and process their emotions when faced with emotionally dissonant and/or complex situations

Provision of this support will enhance a tutor's ability to develop and maintain productive TSRs, thereby creating a pathway to education for some of our most troubled and vulnerable young people. 
RUNNING HEAD: ONE-TO-ONE ALTERNATIVE PROVISION

\section{References}

Bennett, J. B. (1997). The academy, individualism, and the common good. Liberal Education, 83(4), 16-24.

Bennett, J. B. (2003). Academic life: Hospitality, ethics, and spirituality. Williston, VT: Anker Publishing.

Bergin, C., \& Bergin, D. (2009). Attachment in the classroom. Educational Psychology Review, 21(2), 141-170.

Bibby, T. (2010). Education-An 'Impossible Profession'?: Psychoanalytic Explorations of Learning and Classrooms. London: Routledge.

Bion, W. R. (1962). A theory of thinking. London: Routledge.

Bowlby, J. (1969). Attachment and Loss: Attachment; New York. Basic Books.

Bretherton, I., \& Munholland, K.A. (1999). Internal working models revisited. In J. Cassidy \& P.R. Shaver (Eds.), Handbook of attachment: Theory, research, and clinical applications (pp. 89-111). New York: Guilford Press

Browne, L. (2013). Emancipatory research with children in Pupil Referral Units: a Foucauldian perspective on policy and practice (Doctoral dissertation, University of East London).

Carroll, C., \& Hurry, J. (2018). Supporting pupils in school with social, emotional and mental health needs: a scoping review of the literature. Emotional and Behavioural Difficulties, 23(3), 310-325.

Cassidy J (2008) The nature of the child's ties. In Cassidy J. \& Shaver P.R .(Eds.), Handbook of attachment: theory, research and clinical applications, 2nd edn (pp. 3-22). New York: Guilford Press

Cefai, C., \& Cooper, P. (2010). Students without voices: the unheard accounts of secondary school students with social, emotional and behaviour difficulties. European Journal of Special Needs Education, 25(2), 183-198.

Cook, L. (2005). School without walls: reconnecting the disconnected at 14+. Support for Learning, 20(2), 90-95.

Cooper, P. (2010). Social, emotional and behavioural difficulties in young people: The challenge for policy makers. The International Journal of Emotional Education, 2(1), 4-16.

Creswell, J. W. (2009). Research design. Qualitative, quantitative, and mixed methods approaches (3rd ed). London: Sage. 
RUNNING HEAD: ONE-TO-ONE ALTERNATIVE PROVISION

Daniels, H., Cole, T., Sellman, E., Sutton, J., Visser, J. \& Bedward, J. (2003) Study of young people permanently excluded from school (Research Report No 405). London, DfES

Delaney, M. (2009). How Teachers Can Use a Knowledge of Attachment Theory to Work with Difficult-to-Reach Teenagers. In A. Perry (Ed.), Teenagers and Attachment: Helping Adolescents Engage with Life and Learning (pp. 63-96). London: Worth Publishing.

Dennison, A. (2017). Using Interpretative Phenomenological Analysis and psychodynamic theory to explore teachers' experiences of what they perceive as negative pupil behaviour (Doctoral dissertation). Retrieved from http://hdl.handle.net/2381/39317

Department for Education (2012) Training, Support \& Development Standards for Foster Carers: Guidance, London, Department for Education

Department for Education. (2013). Alternative Provision: Statutory Guidance for Local Authorities. London: HMSO

Department for Education/Department of Health. (2014). Special educational needs and disability code of practice: 0-25 years. Statutory guidance for organisations who work with and support children and young people with special educational needs and disabilities. London: DfE/DoH

Dover, J. (2009). The vulnerable child in the classroom. Educational Therapy \& Therapeutic Teaching, 16, 41-48

Downey, J. A. (2008). Recommendations for fostering educational resilience in the classroom. Preventing School Failure: Alternative Education for Children and Youth, 53(1), 56-64.

Duschinsky, R., Greco, M., \& Solomon, J. (2015). The politics of attachment: Lines of flight with Bowlby, Deleuze and Guattari. Theory, culture \& society, 32(7-8), 173-195.

Ecclestone, K., \& Hayes, D. (2009). The dangerous rise of therapeutic education. London: Routledge.

Geddes, H. (2006). Attachment in the classroom: The links between children's early experience, emotional well-being and performance in school. London: Worth Publishing.

Giles, D. L. (2008). Exploring the teacher-student relationship in teacher education: A hermeneutic phenomenological inquiry (Doctoral dissertation). Retrieved from http://hdl.handle.net/10292/537

Giles, D., Smythe, E., \& Spence, D. (2012). Exploring relationships in education: A phenomenological inquiry. Australian Journal of Adult Learning, 52(2), 214. 
RUNNING HEAD: ONE-TO-ONE ALTERNATIVE PROVISION

Gill, K., Quilter-Pinner, H. \& Swift, D. (2017). Making the difference: Breaking the link between school exclusion and social exclusion. London: Institute for Public Policy Research.

Hare, S. Z. (2005). The lehrergarten: A vision for teacher education. Living the questions: Essays inspired by the work and life of Parker J. Palmer. San Francisco, CA: JosseyBass.

Hart, T. (2001). From information to transformation: Education for the evolution of consciousness (Vol. 162). New York: P. Lang.

Hochschild, A. R. (1983b) The managed heart: Commercialization of human feeling. London, University of California Press

Husserl, E. (1999). The essential Husserl: Basic writings in transcendental phenomenology. Bloomington, IN: Indiana University Press.

Jennings, P. A., \& Greenberg, M. T. (2009). The prosocial classroom: Teacher social and emotional competence in relation to student and classroom outcomes. Review of educational research, 79(1), 491-525.

Kazanjian, C. J., \& Choi, S. J. (2016). The person over standardisation: a humanistic framework for teacher learning in diverse school-based contexts. Pedagogy, Culture \& Society, 24(2), 255-267.

Kennedy, J. H., \& Kennedy, C. E. (2004). Attachment theory: Implications for school psychology. Psychology in the Schools, 41(2), 247-259.

Kidger, J., Gunnell, D., Biddle, L., Campbell, R., \& Donovan, J. (2010). Part and parcel of teaching? Secondary school staff's views on supporting student emotional health and wellbeing. British Educational Research Journal, 36(6), 919-935.

Kobak, R., \& Madsen, S. (2008). Disruptions in attachment bonds: Implications for theory, research, and clinical intervention. In J. Cassidy \& P. R. Shaver (Eds.) Handbook of attachment: Theory, research, and clinical applications (pp. 23-47). New York, NY, US: The Guilford Press.

Larkin, M., \& Thompson, A. (2012). Interpretative phenomenological analysis. In A. Thompson \& D. Harper (Eds.), Qualitative research methods in mental health and psychotherapy: a guide for students and practitioners (pp. 99-116). Oxford, UK: John Wiley.

McLoughlin, C. (2010). Concentric circles of containment: A psychodynamic contribution to working in pupil referral units. Journal of Child Psychotherapy, 36(3), 225-239. 
RUNNING HEAD: ONE-TO-ONE ALTERNATIVE PROVISION

Main, M. Hesse, E. \& Hesse, S. (2011) Attachment theory and research: Overview with suggested applications to child custody. Family Court Review 49(3): 426-463.

Malcolm, A. (2019). Turning points in a qualitatively different social space: young adults' reflections of alternative provision. Emotional and Behavioural Difficulties, 1-16.

Marlowe, M. (2011). The relationship-driven classroom: The stories of Torey Hayden. Reclaiming Children and Youth, 20(1), 10.

Maslow, A. H. (1954). The instinctoid nature of basic needs. Journal of Personality, 22(3), 326-347.

Meo, A., \& Parker, A. (2004). Teachers, teaching and educational exclusion: pupil referral units and pedagogic practice. International Journal of Inclusive Education, 8(1), 103120.

Michael, S., \& Frederickson, N. (2013). Improving pupil referral unit outcomes: pupil perspectives. Emotional and Behavioural Difficulties, 18(4), 407-422.

Mihalas, S., Morse, W. C., Allsopp, D. H., Smith, C., Rogers, M., \& Alvarez McHatton, P. (2009). Cultivating caring relationships between teachers and secondary students with emotional and behavioral disorders: Implications for research and practice. Remedial and Special Education, 30(2), 108-125.

Mintz, J. (2007). Psychodynamic perspectives on teacher stress. Psychodynamic practice, 13(2), 153-166.

Murray, C. (2009). Parent and teacher relationships as predictors of school engagement and functioning among low-income urban youth. The Journal of Early Adolescence, 29(3), 376-404.

Nash, P., Schlösser, A. \& Scarr, T. (2016): Teachers' perceptions of disruptive behaviour in schools: a psychological perspective. Emotional and Behavioural Difficulties, 21(2), 167-180.

NICE (2015) Children's Attachment, retrieved from: https://www.nice.org.uk/guidance/ng26 (accessed 11 April 2019).

Nicholson, L., \& Putwain, D. (2015). Facilitating re-engagement in learning: A disengaged student perspective. The Psychology of Education Review, 39(2), 37-41.

Nurmi, J. E. (2012). Students' characteristics and teacher-child relationships in instruction: A meta-analysis. Educational Research Review, 7(3), 177-197.

Palmer, P. J. (1997). The heart of a teacher identity and integrity in teaching. Change: The Magazine of Higher Learning, 29(6), 14-21. 
RUNNING HEAD: ONE-TO-ONE ALTERNATIVE PROVISION

Palmer, P. J. (2004). A hidden wholeness: The journey forward on individual life. San Francisco, CA: Jossey-Bass

Parsons, C. (1999). Social inclusion and school improvement. Support for learning, 14(4), 179-183.

Partridge, K. (2012). Exploring pastoral staff's experiences of their own emotional well-being in a secondary school. Educational and child psychology, 29(4), 121

Perry, B. D. (2001). Bonding and attachment in maltreated children. The Child Trauma Center, 3, 1-17.

Pietkiewicz, I., \& Smith, J. A. (2014). A practical guide to using interpretative phenomenological analysis in qualitative research psychology. Psychological Journal, 20(1), 7-14.

Pirrie, A., Macleod, G., Cullen, M. A. \& McCluskey, G. (2009). Where next for pupils excluded from special schools and pupil referral units? London: Final Report to the Department for Children, Schools and Families.

Pomeroy, E. (1999). The teacher-student relationship in secondary school: Insights from excluded students. British journal of sociology of education, 20(4), 465-482.

Razer, M., \& Friedman, V. J. (2013). Non-abandonment as a foundation for inclusive school practice. Prospects, 43(3), 361-375.

Riley, P. (2010). Attachment theory and the teacher-student relationship: A practical guide for teachers, teacher educators and school leaders. London: Routledge.

Roffey, S. (2012). Pupil Wellbeing-Teacher Wellbeing: Two Sides of the Same Coin? Educational and Child Psychology, 29 (4), 8-17.

Rogers, C. R. (1980). A way of being: the latest thinking on a person-centred approach to life. Boston: Houghton Mifflin.

Sabol, T. J., \& Pianta, R. C. (2012). Recent trends in research on teacher-child relationships. Attachment \& human development, 14(3), 213-231.

Salter-Jones, E. (2012). Promoting the Emotional Well-Being of Teaching Staff in Secondary Schools. Educational and Child Psychology, 29(4), 18-31.

Seager, M. (2014). Who cares for the carers? Keeping compassion alive in care systems, cultures and environments. In S. Shea, R. Wynyard \& C. Lionis (Eds.) Providing compassionate healthcare: Challenges in policy and practice (pp. 40-53). London: Routledge.

Shaver, P. R., \& Mikulincer, M. (2011). An attachment-theory framework for conceptualizing interpersonal behavior. In L. M. Horowitz \& S. Strack (Eds.) 
RUNNING HEAD: ONE-TO-ONE ALTERNATIVE PROVISION

Handbook of interpersonal psychology: Theory, research, assessment and therapeutic interventions (pp. 17-35). Hoboken, NJ: Wiley.

Smith, J. A. (Ed.). (2007). Qualitative psychology: A practical guide to research methods. London: Sage.

Smith, M., Cameron, C., \& Reimer, D. (2017). From attachment to recognition for children in care. The British Journal of Social Work, 47(6), 1606-1623.

Smith, J., Flowers, P., \& Larkin, M. (2009). Interpretative Phoneomological Analysis: theory, method and research. Los Angeles: Sage

Spilt, J. L., Koomen, H. M., Thijs, J. T., \& van der Leij, A. (2012). Supporting teachers' relationships with disruptive children: The potential of relationship-focused reflection. Attachment \& Human Development, 14(3), 305-318.

Starks, H, Trinidad, SB (2007) Choose Your Method: A Comparison of Phenomenology, Discourse Analysis, and Grounded Theory, Qualitative Health Research 17(10): 1372-80.

Tate, S., \& Greatbatch, D. (2017). Alternative Provision: Effective Practice and Post 16 Transition. Manchester, UK. Department of Education

Tompkins, J. (2005). Learning from the workplace: Professional life as an opportunity for personal growth. Living the questions: Essays inspired by the life and work of Parker J. Palmer. San Francisco, CA: Jossey-Bass.

Van Bergen, P., \& Salmon, K. (2010). Emotion-oriented reminiscing and children's recall of a novel event. Cognition and Emotion, 24(6), 991-1007.

Vygotsky, L. S. (1978). Mind in society: The development of higher psychological processes. Cambridge, MA: Harvard university press.

Willis, J., \& Baines, E. (2018). The perceived benefits and difficulties in introducing and maintaining supervision groups in a SEMH special school. Educational Review, 70(3), 259-279.

Wright, A. M. (2009). Every child matters: Discourses of challenging behaviour. Pastoral Care in Education, 27(4), 279-290.

Zapf, D. (2002). Emotion Work and Psychological Well Being: A Review of the Literature and Some Conceptual Considerations. Human Resource Management Review, 12, 237-268. 